\title{
Presenting a Model of Managerial Practical Wisdom in Hospitals
}

Akramsadat Mahdavi, Ph.D. Student, Islamic Azad University, Ardabil Branch,

Department of Management,

Ardabil, Iran,

ORCID: 0000-0002-9236-4850.

Farzad Sattari Ardabili, Assistant Professor, Islamic Azad University, Ardabil Branch,

Department of Management,

Ardabil, Iran,

ORCID: 0000-0001-9734-7921.

Mohammad Kheirandish, Assistant

Professor,

Islamic Azad University, Ardabil Branch,

Department of Management,

Ardabil, Iran,

ORCID: 0000-0002-3913-3017.

Professor Habib Ebrahimpour, IIslamic Azad University, Ardabil Branch,

Department of Management,

Ardabil, Iran,

ORCID: 0000-0003-1848-8246.

Shahram Mirzaei Daryani, Assistant

Professor,

Islamic Azad University, Ardabil Branch,

Department of Management,

Ardabil, Iran,

ORCID: 0000-0002-9358-3190.

\section{Introduction}

If we call the last decade of the twentieth century and the early years of the twenty-first century as the age of learning organizations, the period that sets aside this period and shows itself must inevitably be called the age of wisdom (McKenna, Rooney, \& Boal, 2009). Wisdom is one of the most complex and extensive human concepts. This concept shows the growth of intellectual powers and the development of human behavior (Mousavi et al., 2013a). Wisdom is a multifaceted concept, many of whose meanings differ according to the general orientation of researchers in various times, places and cultures (Po Keung, 2011). Although there is still no generally accepted definition of wisdom, according to Ardelt (2011), there is a kind of collective agreement among researchers that wisdom is "multifaceted and multidimensional" and that these various aspects and dimensions mutually strengthen and support each other.

Some scholars argue that a better understanding of the concept of wisdom by providing specific indices can be in training managers and individuals with 
leadership power and power development against challenges (Jason et al., 2001) decision making, leadership and training (KordNoghabi et al., 2016), social accountability and organizational citizenship behavior (Hays, 2008) to be effective in organizations. Indeed, on the one hand, while wisdom seems to have many advantages in organizations, the difficulty of reaching a practical definition challenges organizations in purposefully employing wise managers and employees, as well as in determining a specific value for wisdom in them (Pourdjam, Siadat, \& Rajaeepour, 2015). However, the existence of wisdom in the organization does not necessarily mean it is applied in the organization, but it is a type of wisdom called "managerial practical wisdom". This wisdom needs "the ability to make good judgments about important but ambiguous issues in life" (Dittman_Cohli, \& Baltes, 1990) and strongly depends on ethics, judgment, insight, intuitive understanding, creativity and other superior types of human intellect and understanding (Rooney \& Mckenna, 2007) and needs serious attention in organizations.

One has to note that in the era of distrust and drastic environmental changes, reliance just on the knowledge and experience of managers is illogical. Moreover, the weakness of managers in the face of complex and multidimensional problems of today and making decisions that sometimes not only do not solve problems, but create new problems for the organization in the implementing process (Danaeifard, Rajabzadeh, \& Salari, 2010) makes the need to pay attention to practical wisdom in the field of management more obvious in the present era.

Considering knowledge, expert and complexity, hospitals are the organizations that are always in the challenge of vital decisions in society. Hospitals are of special significance as the largest and most costly operational unit of the health care system. With their special facilities, these organizations have a critical role in restoring the physical and mental health of the sick people in the community, training specialized personnel, medical research, and ultimately promoting the level of community health. The provision of these services entails high costs for hospitals, including work force payments, equipment and capital goods, raw materials, medicines and supplies (Medin et al., 2013) and the effect of wise management in them have been significantly probed in the Covid-19 Pandemic.

According to Grossman, Dorfman, and Oakes (2020), common approaches to the study of practical wisdom are person-centered and imperfect approaches to defining the issue. He suggests that understanding the underlying processes of practical wisdom calls for an environmental social framework that is the result 
of experience-based insights. Indeed, in examining the empirical evidence by them, special attention has been paid to the underlying characteristics of culture, region, economy and position in the common features of practical wisdom. This approach can provide deeper insights into the seemingly paradoxical results of wisdom given the underlying features. Therefore, the aim of this research is providing a clear model of components, effective factors, growth and development strategies and the results based on the specific conditions and characteristics of practical wisdom management for public hospitals managers, relying on its specific characteristics in Iran's health care system based on the knowledge and experience of specialists, experts and experienced managers of Iranian public universities and hospitals. The managerial practical wisdom management model relies on aspects which include identification causal factors, contextual factors and intervening factors, strategies and results of realizing practical managerial wisdom. The model may help to decision makers in ministry of health to develop managerial capabilities to make wise decisions under stressful environment.

\section{Theoretical foundations}

The concepts of wisdom related to organization and management are usually closely connected to each other and to philosophical and especially psychological frameworks like Robert Sternberg and Baltes models (Izak, 2013). Based on previous studies by Clayton and Birren (1980), wisdom has been defined as the integration of cognitive, reflective, and emotional dimensions. This basic definition of wisdom seems to be in line with most modern and even ancient definitions and descriptions of wisdom, and one of its other advantages is its microscopic nature (Ardelt, 2003).

Kessler (2006) believes that wisdom shows the combination of knowledgebased potential with higher perspectives and practical applications. Wisdom is an action-based concept closely connected with the application of appropriate organizational knowledge during the planning, decision-making and implementation processes. Thus, we define wisdom as "the ability to use knowledge in the best way to determine and reach desirable goals" and learning or acquisition of wisdom as "the process of recognizing judgments and actions based on knowledge" (Bierly, Kessler \& Christensen, 2000). In other words, wisdom is a sign of the ability to use knowledge and judgments correctly and practically in the issues connected with life and carrying out tasks (Pinheiro \& Raposo, 2012). The significant output of wisdom is shown as the results of 
managerial and leadership performance. Application of the wisdom in decision making and managing the conflicts may lead to organizational performance in all aspects including organizational, team and individual levels.

\subsection{Managerial practical wisdom}

Practical wisdom is connected with the experience of good and correct judgments necessarily specific to specific situations and circumstances. Accordingly, the wise person has a very high power of imagination, decisionmaking and action when faced with unknown and forced situations that call for practical sensitivity and some kind of improvisation (Nonaka et al., 2014). Schwartz and Sharp (2010) argue that the development of practical wisdom needs very important emotional and cognitive requirements from individuals.

According to Dickie (2011), practical wisdom combines knowledge and virtue to guide the employees, managers and the organization to make the right decisions. This type of wisdom in management can be considered as a good substitute to technocratic or modernist managerial beliefs: an alternative management scholars have not examined seriously yet (McKenna, 2005).

Additionally, Malan \& Kriger (1998) refer to managerial wisdom as "the ability to detect and observe minor differences between right and wrong, the ability to perceive the meaning of generally contradictory stimuli and cues, to interpret them coherently, to learn new things", and take the necessary actions based on them.

According to Rooney and McKenna (2007), wisdom in practice is a very significant resource for management. Wisdom is basically the practical way of living in a complex world full of doubts and ambiguities. Incorporating practical wisdom into managerial and organizational issues provides important insights into different ways of doing things in the future and reinforcing our understanding of what we do and how we do so.

Indeed, wise thinking and action have a key role in business ethics, development, transformational leadership, organizational citizenship, social responsibility, and democracy in the workplace (Hays, 2008). With its various multidimensional modes, wisdom has a high potential for expanding, deepening and realizing more coherent methods of current managerial and organizational actions (Küpers, 2007). Additionally, it looks that the public concern of the wise man is the public good of all people or the public interest in the conceptual field of wisdom (Mousavi et al., 2013a). 


\subsection{Types of empirical studies regarding wisdom}

In a broad classification, empirical studies in the field of wisdom can be divided into two groups: the first group is the studies called implicit theories that study the meaning of wisdom according to the public. The second group are studies that measure wisdom of the individuals and their rational performance based on the relevant explicit theories and constructs proposed by experts and theorists (Ardelt, 2003). There is often a difference between implicit and explicit theories of wisdom. How wisdom is understood in everyday language and the characteristics of wise people are the questions posed by researchers interested in implicit theories, whereas the explicit approach focuses more on the manifestations of micro-behavior. In other words, as implicit theories are discovered (as they exist in society), explicit theories are created (e.g., by psychologists). However, this distinction, as long as wisdom in concerned is problematic, as it is possible to combine the fields of discovery and creation and there is no need to understand them separately. According to some evidence, explicit theories in studies usually derive from the implicit theories of psychological theorists (Dickie, 2011) and allow practical and hypothetical studies to explain and validate the model (Limas \& Hansson, 2004).

In this part, a number of related studies conducted from 1997 to 2020 in the field of practical and managerial wisdom are summarized in table 1.

Table 1. Related studies conducted 1997-2020

\begin{tabular}{|c|c|c|}
\hline Research & Subject & $\begin{array}{l}\text { The results / components } \\
\text { or definitions of wisdom presented }\end{array}$ \\
\hline $\begin{array}{l}\text { Wink and Hel- } \\
\text { son (1997) }\end{array}$ & $\begin{array}{l}\text { Presenting a standard practi- } \\
\text { cal wisdom self-assessment } \\
\text { scale using the ACL attribute } \\
\text { checklist }\end{array}$ & $\begin{array}{l}\text { Understanding the complexities and limitations of } \\
\text { knowledge, integrating thoughts and feelings, deep } \\
\text { philosophical / spiritual perspectives }\end{array}$ \\
\hline $\begin{array}{l}\text { Sternberg } \\
(2003)\end{array}$ & $\begin{array}{l}\text { WICS model (leadership } \\
\text { model in the organization } \\
\text { with components of wisdom, } \\
\text { intelligence, and creativity) }\end{array}$ & $\begin{array}{l}\text { Every wise manager or leader in the organization } \\
\text { has to have these skills: creative problem-solving } \\
\text { skills, analytical skills to evaluate ideas, and practi- } \\
\text { cal skills to implement ideas }\end{array}$ \\
\hline $\begin{array}{l}\text { Reynolds } \\
(2003)\end{array}$ & $\begin{array}{l}\text { Presenting a scale for mana- } \\
\text { gerial wisdom }\end{array}$ & $\begin{array}{l}\text { Of the } 63 \text { micro-related features in the subject litera- } \\
\text { ture, } 20 \text { most considered features were ranked by } \\
\text { executives who had the highest-ranking ability and } \\
\text { the lowest ranking age }\end{array}$ \\
\hline
\end{tabular}




\begin{tabular}{|c|c|c|}
\hline Gibson (2007) & $\begin{array}{l}\text { Presenting a model of mana- } \\
\text { gerial practical wisdom }\end{array}$ & $\begin{array}{l}\text { Three characteristics of practical wisdom are high- } \\
\text { lighted by this model: the way of developing wis- } \\
\text { dom over time through contemplative attention to } \\
\text { the meaning of experiences, attention to cognitive } \\
\text { designs, the use of wisdom of its active elements } \\
\text { (enablers) as a whole and in perfect harmony with } \\
\text { each other }\end{array}$ \\
\hline $\begin{array}{l}\text { McKenna et al. } \\
\text { (2009) }\end{array}$ & $\begin{array}{l}\text { Presenting a set of five prin- } \\
\text { ciples for designing the char- } \\
\text { acteristics of wise leaders } \\
\text { and managers }\end{array}$ & $\begin{array}{l}\text { (1) Using evidence and careful observation, (2) } \\
\text { focus on irrational and subjective elements while } \\
\text { making decisions, (3) valuing humanity and its vir- } \\
\text { tuous consequences, (4) taking possible and practi- } \\
\text { cal steps in the direction of daily life, (5) being ac- } \\
\text { curate and understanding the aesthetic dimensions } \\
\text { of the task }\end{array}$ \\
\hline $\begin{array}{l}\text { Thomas et al. } \\
(2017)\end{array}$ & $\begin{array}{l}\text { Introducing the new SD-WIS } \\
\text { scale based on understand- } \\
\text { ing the structure of wisdom } \\
\text { as a psychological trait }\end{array}$ & $\begin{array}{l}\text { (1) General knowledge of life and social decisions, } \\
\text { (2) emotional regulation, (3) socially beneficial be- } \\
\text { haviors (practicality), (4) self-awareness, (5) value } \\
\text { relativism, and (6) assertiveness }\end{array}$ \\
\hline $\begin{array}{l}\text { Bachmann, } \\
\text { Habish and } \\
\text { Dierskmeier } \\
\text { (2018) }\end{array}$ & $\begin{array}{l}\text { A review of the literature on } \\
\text { practical wisdom from the } \\
\text { perspective of philosophical, } \\
\text { spiritual, psychological and } \\
\text { managerial sciences }\end{array}$ & $\begin{array}{l}\text { Despite the apparent differences in terms of ap- } \\
\text { proach and methodology between the mentioned } \\
\text { sciences, the results are in fact complementary and } \\
\text { practical wisdom in the field of management com- } \\
\text { bines these results for practical use. }\end{array}$ \\
\hline $\begin{array}{l}\text { Peter Massing- } \\
\text { ham (2019) }\end{array}$ & $\begin{array}{l}\text { A case study of practical wis- } \\
\text { dom in retirees }\end{array}$ & $\begin{array}{l}\text { The use of practical wisdom is considered as an } \\
\text { organizational framework for professional knowl- } \\
\text { edge. To bridge the gaps in ability in the new gen- } \\
\text { eration of employees, the wisdom and experience } \\
\text { of retirees can be a valuable source of knowledge } \\
\text { and play a facilitating role in the organization }\end{array}$ \\
\hline $\begin{array}{l}\text { Grossman, } \\
\text { Dorfmana and } \\
\text { Oakes (2020) }\end{array}$ & $\begin{array}{l}\text { The study of wisdom as an } \\
\text { environmental social phe- } \\
\text { nomenon }\end{array}$ & $\begin{array}{l}\text { Understanding the underlying processes of prac- } \\
\text { tical wisdom needs a social-environmental frame- } \\
\text { work that is the result of experience-based insights. } \\
\text { In this study, the underlying characteristics of cul- } \\
\text { ture, region, economy and situation in the common } \\
\text { characteristics of practical wisdom have been con- } \\
\text { sidered }\end{array}$ \\
\hline $\begin{array}{l}\text { Danaeifard et } \\
\text { al. (2010) }\end{array}$ & $\begin{array}{l}\text { An analysis of the pillars of } \\
\text { management wisdom from } \\
\text { the perspective of NAJA } \\
\text { managers }\end{array}$ & $\begin{array}{l}\text { Five more features were added to the } 20 \text { features } \\
\text { presented by Reynolds (2003), and examined in } \\
\text { both individual and interpersonal dimensions }\end{array}$ \\
\hline
\end{tabular}




\begin{tabular}{l|l|l}
$\begin{array}{l}\text { Mousavi et al. } \\
(2013 \mathrm{~b})\end{array}$ & $\begin{array}{l}\text { Management and organiza- } \\
\text { tional micro-study based on } \\
5 \text { dimensions and at 4 levels }\end{array}$ & $\begin{array}{l}\text { Examining managerial and organizational wisdom } \\
\text { on the five pillars of logic, ethics, aesthetics, cogni- } \\
\text { tion and metaphysics at four levels: individual, in- } \\
\text { terpersonal, organizational and strategic }\end{array}$ \\
\hline Moradi (2015) & $\begin{array}{l}\text { Presenting a model of wis- } \\
\text { dom-based organization in } \\
\text { government offices }\end{array}$ & $\begin{array}{l}\text { Presenting a model of wisdom-based organization } \\
\text { with 5 variables: "leadership and management } \\
\text { style", "ethical principles", "learning and knowl- } \\
\text { edge management", ,judgment and decision-mak- } \\
\text { ing" and "corporate culture" }\end{array}$ \\
\hline $\begin{array}{l}\text { KordNoghabi } \\
\text { et al. (2016) }\end{array}$ & Wisdom evaluation in Iran & $\begin{array}{l}\text { Validation of 3 scales in wisdom evaluation, includ- } \\
\text { ing Ardelt 3D scales, Webster self-assessment and } \\
\text { adult self-avoidance }\end{array}$ \\
\hline $\begin{array}{l}\text { Rezaian et al. } \\
\text { (2019) }\end{array}$ & $\begin{array}{l}\text { Designing and explaining } \\
\text { the organizational micro- } \\
\text { assessment model in higher } \\
\text { education in Yemen }\end{array}$ & $\begin{array}{l}\text { Identifying micro-organizational components like } \\
\text { strategic thinking and organizational structure, vir- } \\
\text { tue and ethical principles, decision-making-leader- } \\
\text { ship and human resource management, collabora- } \\
\text { tion and pragmatism, innovation and creativity }\end{array}$ \\
\hline $\begin{array}{l}\text { Monaza- } \\
\text { miTabar et al. } \\
\text { (2019) }\end{array}$ & $\begin{array}{l}\text { Construction and validation } \\
\text { of wisdom test based on Ira- } \\
\text { nian components }\end{array}$ & $\begin{array}{l}\text { Construction of Iranian wisdom test including cog- } \\
\text { nitive, emotional, flexibility and openness to experi- } \\
\text { ence, self-avoidance/purposefulness and meaning } \\
\text { search }\end{array}$ \\
\hline $\begin{array}{l}\text { Rahmani and } \\
\text { Dialameh } \\
\text { (2019) }\end{array}$ & $\begin{array}{l}\text { The model of wisdom-based } \\
\text { leadership from the perspec- } \\
\text { tive of Islam in educational } \\
\text { organizations }\end{array}$ & $\begin{array}{l}\text { Presenting a model of wise leadership with four } \\
\text { factors (revelatory rationality, strengthening the } \\
\text { observer of reality, growth prevention, timely op- } \\
\text { eration) and thirteen components }\end{array}$ \\
\hline
\end{tabular}

Source: own study

\section{Methodology}

The study was qualitative, in terms of fundamental orientation, exploratory in terms of purpose, inductive in terms of approach, and interpretive in terms of research philosophy. Regarding the time horizon, the study was cross-sectional (2019-2020) in Public hospitals in Iran which are managed by Ministry of Health and Medical Education. The strategy used was Grounded theory and Corbin and Strauss paradigm model (Corbin \& Strauss, 2008) was used to present the final model. Content analysis technique was used in the study to analyze the contents of the interviews. The reason for using Grounded theory in the study was due to the need to examine and use the experiences and views of knowledgeable people to formulate a theory (Creswell, 2012). 


\subsection{Measurement}

A researcher-made open questionnaire designed based on Corbin and Strauss paradigm model according to research objectives which is concentrated on identification causal factors, contextual factors and intervening factors, strategies and results of realizing practical managerial wisdom. Additionally, semi-structured interviews were used to collect information due to the lack of resources on managerial practical wisdom and to complete previous studies based on the views of executives and experts in this field. Firstly, the initial interviews were conducted with three experienced and knowledgeable managers and faculty members based on semi-structured questions, and the initial questions that were listed in line with the main research questions were reviewed and corrected according to the results of these interviews. The axes and questions of the interview were reviewed and corrected according to the answers provided and the feedback obtained from the initial interviews used in subsequent interviews.

\subsection{Population and sample}

The population was the hospital managers, experts (professors), health services management, health policy of medical universities with education and scientific and practical experiences in the field of hospital management, human resources and the subject examined.

According to the strategy of this study (Grounded theory), the participants were selected using purposive sampling method. In purposive sampling, one of the non-probability sampling methods in qualitative studies, the researcher selects participants according to the set goals and consciously who can be effective in understanding the research problem and the central phenomenon under study (Creswell, 2012). Thus, the professors and faculty experts of the university were selected as a sample due to benefiting from the knowledge of hospital managers because of their experience in the subject.

Theoretical (judgmental) sampling was used for the adequacy of sampling, where the researcher simultaneously collects, encodes and analyzes the data. The criterion for judging when to stop theoretical sampling is the adequacy of categories or theory: sampling continues until the next sample does not add a complementary content to the previous content (Danaeifard \& Emami, 2007). By conducting 19 interviews and completing the coding of the interviews, the theoretical saturation was obtained and the next two interviews confirmed

27

AKRAMSADAT MAHDAVI

FARZAD SATTARI ARDABILI

MOHAMMAD KHEIRANDISH

HABIB EBRAHIMPOUR

SHAHRAM MIRZAEI DARYANI 
the theoretical saturation (21 interviews were conducted). Table 2 shows the characteristics of the interviewees.

Table 2. Demographic characteristics of the interviewees

\begin{tabular}{|c|c|c|c|c|c|}
\hline \multicolumn{2}{|c|}{ Feature dimensions } & \multirow{2}{*}{$\frac{F}{6}$} & \multicolumn{2}{|l|}{ Feature } & \multirow{2}{*}{$\frac{\mathbf{F}}{16}$} \\
\hline \multirow{2}{*}{ Gender } & Female & & \multirow{2}{*}{$\begin{array}{l}\text { Education } \\
\text { level }\end{array}$} & $\begin{array}{l}\text { Specialized and professional } \\
\text { doctorate }\end{array}$ & \\
\hline & Male & 15 & & Bachelor and Master & 5 \\
\hline \multirow{2}{*}{ Field of work } & Faculty member & 14 & \multirow{2}{*}{$\begin{array}{l}\text { Work } \\
\text { history }\end{array}$} & Less than 10 years & 5 \\
\hline & Hospital Manager & 7 & & More than 10 years & 16 \\
\hline
\end{tabular}

Source: own study

\section{Data analysis}

Given the stages of data analysis in the Grounded theory and as the model used in this study is the Corbin and Strauss paradigm model based on identifying the axial phenomenon, causal conditions, underlying and intervening factors, strategies, consequences and the relationship between them, data analysis was performed according to the following steps.

\subsection{Open coding}

It is an analytical process by which the general characteristics of the studied phenomenon and the variables related to the phenomenon are identified, named and classified. At this step of data analysis, code labeling was done based on interviews and the researcher tried to adhere to people's perceptions of the respondents as much as necessary to avoid any possible and unwanted bias as much as possible. Categorization and conceptualization were done after extracting the initial codes, and the concepts were formed continuously and with continuous comparison of revisions and final concepts and categories.

\subsection{Axial coding}

Open coding ends with defining concepts and categories (classes). At this time, the researcher has some classes to determine their relationship in real space. This action is done in the axial coding stage (Bazargan, 2008). 
At this stage, the researcher re-examined the data that was broken down into concepts and categories to link between one class and the concepts contained in the other categories based on the paradigm model of Corbin and Strauss . Indeed, the researcher selected and examined a category as the axial phenomenon and then related other categories based on the model. The output of the axial coding stage was a paradigm model that besides the axial phenomenon includes causal conditions, governing context or underlying factors, intervening factors, strategies and consequences.

At this stage, selective coding is used to facilitate the integration of identified categories in the open and axial coding stages as an emerging theory (Sohrabi et al., 2013).

\subsection{Selective coding}

At this stage, the categories derived from the axial coding are analyzed in general and the researcher formulates a theory about the relationship between the categories obtained in the paradigm model. Indeed, the obtained items were integrated during selective coding to develop a theoretical model after the relationship between classes or categories was identified in open and axial coding.

\section{Validation and quality evaluation of Grounded theory}

Study without scientific accuracy in any quantitative or qualitative study lacks the necessary value and loses its usefulness (Corbin \& Strauss, 2008). This issue in the field of qualitative studies is associated with differences of opinion between researchers and experts. According to scholars in qualitative research, instead of using conventional approaches in the field of quantitative research, the method of conducting the study must be carefully considered. The issue that Danaeifard et al. (2012) have stated as research audit refers to the mechanisms used to ensure the validity, reliability and scientific accuracy of a research during the research process to identify errors, leading to more analytical results. Corbin and Strauss (2008) proposed the acceptability criterion instead of the validity and reliability criteria in quantitative studies to evaluate research based on Grounded theory. Acceptability means to what extent the results are successful and reliable in showing the experiences of the researcher and reader participants on the point examined. The following are the steps taken to ensure the quality of the study in its course. 


\subsection{Theoretical saturation}

Achieving the level of data adequacy in obtaining research goals has always been one of the most significant indices for evaluating the accuracy of scientific research. In qualitative research approaches, this becomes meaningful by reaching the level of theoretical saturation (Strauss \& Corbin, 2008). Creswell (2012) argues that sufficient attention to the issue of theoretical saturation is one of the four pillars of measuring the validity of qualitative research based on Grounded theory method.

As stated, theoretical saturation was obtained in the study after 19 interviews with the next confirmation by two interviewers. Accordingly, one can ensure that the category of theoretical saturation in this study is properly observed and data collected up to the level properly continued.

\subsection{Fit}

Fit is a measure that shows how much the result of the Grounded theory fits with the mental structure of individuals about the phenomenon under study (Corbin \& Strauss, 2008). Other members of the research team evaluated this criterion during the study. In addition, after preparing the model, the result was provided to experts outside the interviewees who were both familiar with the research problem and were proficient in the Grounded theory method. The feedback obtained showed that the result was in line with the phenomenon.

\subsection{Comprehensibility}

Comprehensibility is a criterion, showing the extent to which the results are comprehensible to individuals in the field where the study was conducted, and the extent to which the results show the real world of the interviewees (Corbin \& Strauss, 2008). To measure the achievement of this criterion, the results as a paradigm model and related explanations were presented to 5 participants in the interviews and the results showed that the results and the paradigm model obtained for them were comprehensible and highly consistent with their ideas during the interview.

\subsection{Generalizability}

This criterion indicating that the results of the research cover the various dimensions of the studied phenomenon so that it can determine the possible 
changes and fluctuations in the phenomenon and the results include the various dimensions of the studied phenomenon properly realized (ibid). In this study, the depth of the interviews and the allocation of sufficient time to them and conducting 21 interviews with people working at different levels of executives and faculty members of health services management and health policy and using the experience of experts tried to properly meet the generalizability criterion. The variety and fluctuations in the cases was the base for the formation of the final model. In addition, the study made an attempt to select the words of the paradigm model with great care, so that besides covering the needs of the study, the relevant model has the necessary comprehensiveness.

\subsection{Reliability}

The degree to which the study results show the research data and the uniqueness of findings over time and space using the experiences of experts and their respective managers is called reliability (Lincoln \& Guba, 1998). Four months of interviews with relevant experts and specialists, reviewing the interviews conducted on paper and evaluating the interpretations made by the researcher and colleagues, reporting the results to five participants and getting feedback on the interpretations of the researcher from various aspects described by them, re-interview with two interviewees after the final model was developed for further refining the formulated theories were done, which resulted in the closure and refinement of interpretations.

Indeed, the audit strategies used in the study were the sensitivity of researchers, methodological coherence (documentation of research steps), sample fitness, repetition of a finding and the use of feedback from relevant informants and experts, interviews with experienced managers and faculty experts in health services management and health policy ensured the optimization of data quality and showed the reliability.

\section{Results}

Table 3 shows the codes, concepts and categories based on the interviews conducted in the study. The axial phenomenon shows the main theme of the study (Aramoon et al., 2018) and a subjective form of the phenomenon that is the base of the process (Danaeifard \& Emami, 2007). In this study, it is defined based on the focus of the answers provided and the extracted concepts and categories of managerial practical wisdom. Table 3 is an example of coding, creating concepts and categories extracted in this study. 
Figure 1. shows the paradigm model view of managerial practical wisdom

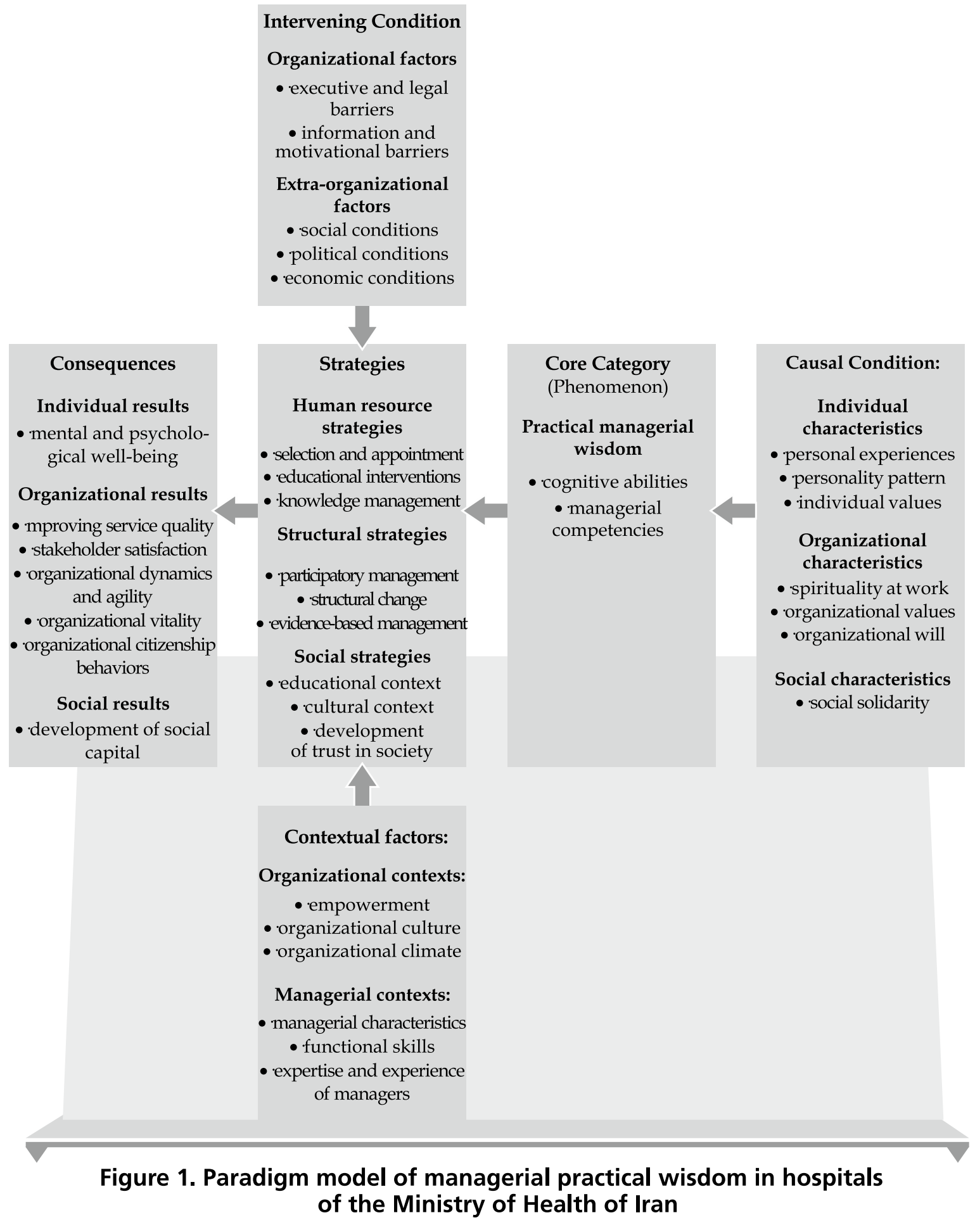

Source: own study 
Table 3. Extracted codes, concepts and categories

\begin{tabular}{|c|c|c|}
\hline \multicolumn{3}{|c|}{ Categories related to the axial phenomenon } \\
\hline Categories & Concepts & Codes \\
\hline \multirow{2}{*}{$\begin{array}{l}\text { Managerial } \\
\text { practical } \\
\text { wisdom }\end{array}$} & $\begin{array}{l}\text { Cognitive } \\
\text { abilities }\end{array}$ & Social cognition, flexibility, reflection, decision making \\
\hline & $\begin{array}{c}\text { Managerial } \\
\text { competencies }\end{array}$ & $\begin{array}{l}\text { Commitment and accountability, strategic pragmatism, } \\
\text { problem-solving creativity, managerial knowledge and } \\
\text { experience, leadership, courage and determination }\end{array}$ \\
\hline
\end{tabular}

Source: own study

\section{An analysis of the research paradigm model}

In this study, the data analysis procedure, which leads to the creation of a theoretical model, describes the main phenomenon in question, managerial practical wisdom. Indeed, five theoretical theorems are presented as follows in the selective coding stage to explain the research results and the dimensions of the paradigm model.

\subsection{Causal factors}

According to the results and paradigm model, the most significant causal factors for the realization of managerial practical wisdom in managers of public hospitals under the Ministry of Health of Iran include three categories of individual factors (personal experiences, personality model, individual values of managers), organizational factors (spirituality at work, organizational values, and organizational will) and social factors (social solidarity). All of these factors are related to the cultural context. The cultural factors, especially regional culture; has the underlying role that the organizational culture, values and ethics are in accordance with its applications.

\subsection{Core Category}

The results show that two aspects of management actions play the main role of practical wisdom; Cognitive abilities and Managerial competencies. Cognitive abilities related to knowledge and mind analysis or virtue for decision making. Organizations need to enhance their ability to utilize the decision-making 
capacity (Darville, 2019) which is achievable through top leaders. Managerial capabilities are the tools for converting this knowledge to product of action of decision.

\subsection{Strategies}

Human resource strategies (selection and appointment of managers, educational interventions and knowledge management in public hospitals), management strategies (participatory management, structural changes, and evidence-based management) and social strategies (educational context, cultural context and trust development in society) are the adoptable strategies that can interpreted as the results of the realization and development of practical wisdom in the managers of hospitals of the Ministry of Health of Iran. For being practically wise, managers needs high cognitive abilities along with managerial capabilities. The combination would be shown as high performance in using three strategies, including Human resource, structural and social strategies.

\subsection{Contextual factors}

They bring about providing organizational contexts (empowerment, organizational culture, and organizational climate) and managerial contexts (managerial characteristics, performance skills, expertise and experience of managers) specific organizational contexts by affecting the strategies proposed to reach the managerial practical wisdom in the managers of the hospitals of Ministry of Health and Medical Education.

\subsection{Intervening factors}

Organizational factors (executive and legal barriers, information and motivational barriers) on the one hand and extra-organizational factors (social conditions, political and economic conditions) on the other as interference can delay or impede the realization of managerial practical wisdom in public hospitals.

\subsection{Consequences}

Adopting the strategies stated to realize managerial practical wisdom in the hospitals of the Ministry of Health and Medical Education will have the following individual, organizational and social consequences: 
Individual results are the mental and psychological well-being, organizational outcomes are service quality improvement, stakeholder satisfaction, organizational dynamism and agility, organizational vitality and organizational citizenship behaviors, and social outcomes is social capital development.

\section{Discussion}

The study was qualitative study trying to provide a model explaining managerial practical wisdom in managers of hospitals of the Ministry of Health and Medical Education of Iran. The practical wisdom management is critical given the rough situation in Iranian hospitals which managers are faced due to sanctions, lack of equipment and pressure of expected services in the society. However, the factors which are usually studied as factors affecting wisdom in western societies are cultural based and the wise managers in Iran's hospitals face with different elements in decision making. Therefore, we tried to review and match the results with the results of previous studies in the field of wisdom and practical wisdom in the field of management.

Managerial practical wisdom, in this study, is considered as the axial phenomenon in the presented paradigm model including cognitive abilities and managerial competencies. To support the results of the study, one can refer to the studies of Schwartz (2011) and Schwartz and Sharp (2010) on the significance of cognitive skills as a characteristic of people with practical wisdom. Other similarities and consistency of the results of the study in identifying the dimensions and components of practical wisdom with other studies are the definition of cognitive dimensions along with the components of reflection and empathy as components of wisdom by Ardelt (2003). The others are the dependence of wisdom on cognition and thinking in Sternberg study (2005), and focusing on cognitive functions in the study of components of wisdom in the Berlin paradigm of wisdom (Baltes \& Staudinger, 2000). Moreover, they are microassessment as a cognitive feature based on individuals' performance in problem solving and decision making (Kunsmann, 2007). Emphasizing the importance of practical wisdom in strategic management (Nonaka \& Toyama, 2007), stating the importance of long-term perspectives, result and practice orientation of wise managers and leaders in the WICS model presented by Sternberg (2005), stating result orientation and pragmatism as components of wisdom in NahjulBalagha by Ranjbarian et al. (2011) are of the other cases. Emphasizing the significance of wise leadership in organizations by Rooney and McKenna (2007), referring to the nature of guidance and leadership and conflict resolution as the competencies of 
wise leaders and the implementation of wisdom as a correct and timely action in the field of management to achieve common and collective benefits by Rahmani \& Dialameh (2019) is another case. The others are referring to the significance of knowledge, personal and organizational experience of managers as components of wisdom (Reynolds, 2003, Pourdjam et al., 2015) and the need for courage to judge and act wisely (McKenna et al., 2009). It has to be noted that a similar study that has examined the dimensions and components of practical wisdom in hospital managers has not been available for comparison at the time of writing the paper.

On the other hand, according to the results of the study, the managers agreed the factors affecting the realization of managerial practical wisdom in the managers of these hospitals and experts in the three groups of causal factors, underlying factors and intervention factors were agreed as follows:

The causal factors identified in the study are individual factors (personal and professional life experiences, especially hard and challenging experiences, personality traits, emotional stability of the manager and adherence to his/ her and the organization's value systems), organizational factors (spirituality at work, accountability and commitment to the values of the organization, and organizational will) and social factors (social solidarity from the compassion in society and belonging to each other). These results are in line with the following studies in addressing the issue of personal knowledge and experience as a component of wisdom on the scale of Levenson (2005), pointing to challenging experiences as a prerequisite for wisdom (Webster, 2010), and emphasis on ageand career-related experiences by Grossmann (2017). The results were also in line with the studies on attention to personality traits in the development of wisdom and explaining part of wisdom with personality indices by Kunzmann and Baltes (2005), Staudinger, Dorner and Mickler (2005) attention to spirituality as a kind of wisdom in the organization and the need for leaders to support spirituality for growth wisdom in the organization by Zaidman and Goldstein-Gidoni (2011). They were also consistent with the studies of the role of promoting organizational values and culture in wise action (Bierly et al., 2000), emphasis on organizational willpower in supporting wisdom and wise behavior in Schwartz (2011) and Schwartz and Sharp Studies (2010), pointing to the importance of paying attention to the welfare and interests of others in the realization of wisdom in the study of Staudinger and Gluck (2011). The other consistent studies were emphasizing the preservation of community interests and valuing social relations in wise leaders (Rahmani \& Dialameh, 2019) and pointing to the importance Social factors have been well matched in the growth of wisdom by Grossman (2017). 
Concerning the underlying factors of managerial practical wisdom in the study, the results were organizational contexts (empowerment of managers and employees, value-based organizational culture, organizational climate of trust in the organization, appropriate formal and informal communication) and managerial contexts (managerial characteristics like trust and participation of the employees mastering the rules, functional, perceptual, analytical, communication, judgment and decision making skills, creative thinking and problem solving and expertise and scientific and practical experience of managers). The results are in line with the studies conducted by Bierly et al. (2000) regarding the transmission of wisdom in wise people through education to others, participatory and group learning with common goals (Grossmann, 2017), the dependence of the relative weight of wisdom parameters on the content, or culture of the environment and the need to know the underlying conditions of wisdom (ibid). The results of Rahmani and Dialameh (2019) on building trust and participation of employees by wise managers and leaders are in line with this study. The importance of perceptual and analytical skills, judgment and decision-making skills, creative thinking and problem solving in wise managers and leaders (Sternberg, 2005; McKenna et al., 2009; Danaeifard et al., 2010; Rahmani \& Dialameh, 2019), attention to the importance of communication skills as one of the individual characteristics of managers in the studies of Danaeifard et al (2010) and Rahmani and Dialameh (2019) referring to the expertise and experience of wise leaders in educational organizations by Rahmani and Dialameh (2019) are of the results in line with our study.

The third class of the factors affecting the managerial practical wisdom is called intervening factors and in this study in the form of organizational factors (executive and legal instructions in case of becoming redundant bureaucracies, creating long decision chains, selecting managers' tastes or quick changes at the same time, not providing information and motivational contexts for familiarity with the concepts and definitions of practical wisdom for managers and employees, inequality in the possibility of managerial jobs and discrimination in the workplace) and extra-organizational factors (social problems in society with their samples in increase of individualistic and self-centered thinking in society, psychological climate of distrust and reduced trust in the government system or economic and political conditions like the effects of political decisions, sanctions and financial and economic crises and lack of funds and resources in public hospitals).

Regarding this, Schwartz (2011) and Schwartz and Sharp (2010) consider the limitations of laws and regulations and redundant administrative bureaucracies 
as hurdles to the realization of practical wisdom in organizations and Kok (2010) points to the role of management and bureaucratic systems as an obstacle to the realization of wisdom in the organization. Moreover, management changes by Grossmann (2017) are of the examples of unpredictable work environments as an obstacle to the realization of wisdom. Furthermore, the difficulty of examining and achieving the concepts of wisdom by Sternberg (1998), the lack of a clear picture of the role of wisdom in industrial societies and the difficulty of systematically studying wisdom (Aubrey \&Cohen, 1995), the neglect of some organizations to the public interest (Nonaka et al., 2014), individualistic goals for achieving popularity or immediate rewards, and the role of monopolistic minds environments in preventing wisdom (Grossmann, 2017), unpredictable economics are of the studies similar to the results of previous studies in this regard.

Human resource strategies include the selection and appointment of experienced and wise managers, considering emotional and social intelligence criteria in choices, meritocracy in appointments. Educational interventions involve teaching creative thinking techniques, critical thinking and functional capacity development, knowledge management in hospitals by creating effective organizational communication, succession and coaching of managers and facilitating participatory learning. Regarding this, the consistent results of Rooney and McKenna (2007) on the importance of human resource management as a key element in the entry of wisdom into business, maintaining, and retaining it, the importance of selection and recruitment systems for managers and employees can be cited. Moreover, the value of wise managers (Mousavi et al, $2013 b)$, educational action with a focus on perceptual orientation and awareness of individuals and coaching, practical exercises and knowledge sharing as the best measures for wisdom development (Kessler \& Bailey, 2007), knowledge sharing and management as a powerful tool to turn data into meaningful information and the realization of wisdom in the organization (Dickie, 2011) and the importance of knowledge management in micro-organizations (Moradi, 2015) are of the other consistent studies.

The second group of strategies of the study is management strategies, including participatory management and facilitation of participation in affairs, structural changes like job-to-employee fit, flexibility in structures and rules, delegating sufficient authority and independence of action to managers and management based on evidence (Facilitating scientific evidence and evidencebased decision making). The results of Kessler and Bailey (2007) regarding the role of participation, cooperation and teamwork, focus on designing the 
structure and relationships of stakeholders as the best development measures and practical use of wisdom, emphasizing the greater likelihood of observing wisdom in multi-minded interaction and participation (Staudinger, 1996) confirm the mentioned results regarding management strategies for the realization and growth of wisdom in individuals, managers and organizations. The role of appropriate interactions with others and the desire to learn for the growth of wisdom (Brown, 2004), attention to free and separate structures as a way to overcome the limiting boundaries of wisdom (Bierly et al., 2000) also confirm this. Other studies are Danaeifard et al. (2010) on the proper delegation of authority to managers to reach managerial wisdom and point to the importance of organizational structures in the growth and development of practical wisdom in organizations by Schwartz (2011) and Schwartz and Sharp (2010) that confirm the results regarding management strategies for the realization and growth of wisdom in individuals, managers and organizations. It has to be noted that no evidence was found regarding evidence-based management as a strategy for realizing and developing practical wisdom in managers or organizations.

The third category of strategies in the present study, "Social strategies," includes training to create opportunities for thinking and decision-making, and teaching empathy and wise concepts at home and school. They were also teaching life skills, cultural context, adherence to laws and civil rights, developing religious beliefs and ultimately the development of trust in society with the sincerity of the government and the executive apparatus and the reduction of discrimination and the development of equality in social life. Regarding this, it is possible to suggest the inclusion of teaching specific skills and ways of thinking in school curricula and designing curricula based on wisdom, encouraging students to learn wisdom and the importance of teaching wisdom in schools and universities by Sternberg (2004 and 2005). Sternberg et al. (2009) and Asaadi et al. (2013), emphasis on explaining the concepts of wisdom in educational environments by Rahmani and Dialameh (2019), and the role of life and education type received in the formation of wisdom (KordNoghabi et al., 2018) are the results and studies confirming social strategies in our study. The other studies confirming our results were the need to teach creative thinking in rich educational environments like universities to deliver wise people to society (Ghorbani \& Khormaei, 2018), the dependence of the significance of various dimensions of wisdom on the orientations of different cultures (Takahashi \& Bordia, 2000; Takahashi \& Overton, 2005; Yang, 2001), the effect of religious culture on wisdom in society 
(Paulhus et al., 2002), the effect of cultural context and the significance of trust and close relationship between the individual and society on the formation of wisdom in society (KordNoghabi et al., 2018).

The results about mental and psychological well-being for managers, feelings of inner peace and satisfaction, feelings of competence and self-confidence, popularity and are in line with the studies by Holliday and Chandler (1986) and Ardelt $(2000 ; 2009)$ regarding the feelings of satisfaction with life and feeling happy as the results of wisdom in individuals. The results were also in line with those of relationship between well-being or well-being as a consequence (Ardelt \& Jeste, 2016), pointing to leading the understanding of wisdom to improve life satisfaction and helping to cultivate wise leaders in Staudinger (1997), attention to the positive effect of wisdom on life quality (Bangen et al., 2013) and emphasizing the potential role of wisdom in the sense of personal well-being by Cloninger (2012).

Another category of the results of the realization of practical wisdom in the managers of hospitals of the Ministry of Health known as organizational results has been considered in this study. These results include improving service quality and reducing the costs of hospital errors, optimal use of the least available resources, gaining trust and satisfaction of clients and increasing the job satisfaction of managers and service providers. These results also included organizational dynamism and agility by accelerating responsiveness and decisions organizational flexibility in action and facilitation of affairs to solve crises, organizational vitality resulting from appropriate and optimal interaction with employees and managers, active participation in affairs and decisions, a sense of security and trust in the system and creating satisfaction and motivation in employees. These are seen in Schwartz (2011) regarding the role of practical wisdom in improving organizational decisions like in hospitals, achieving the real goals of the health system and increasing client satisfaction, also satisfaction in the organization, the importance of wise employees in the government system and their role in ensuring the quality of services to citizens and promoting the value of public and government services, especially in health and education (McKenna, 2005). Moreover, pointing to the proximity of individual and organizational goals and thus job satisfaction with increase in wisdom in the organization in Plickert, Kay \& Hagan (2017), attention to mutual satisfaction in providing organizational services with wisdom (Kok, 2010) are in line with our results. The emphasis on the role of wisdom flows in job satisfaction and the quality of manager-employee relationships by Küpers (2007), flexibility in action, speed in decision-making and accountability (of the components 
of organizational agility), the ability to face challenges, facilitation while using existing rules as wisdom results are among these studies. Practical wisdom in Schwartz (2011), Birren and Fisher (1990), KordNoghabi and Beiranvand (2016), the effect of leader wisdom on lasting happiness in the organization and its effect on the feeling of happiness or cheerfulness in employees (Bergsma \& Ardelt, 2012) are in line with our results. Pointing to the effect of wise thoughts and actions on organizational citizenship behaviors and social accountability(Hays, 2008), attention to organizational citizenship behaviors or commitment as the result of wisdom by Schwartz (2011) and Schwartz and Sharp (2010), the significant relationship between wisdom-based approaches and organizational outcomes like efforts, satisfactory the quality of communication in the organization (Barbuto\&Wheeler, 2006) have been other results in line with our results. Also, the relationship between ethical leadership and employee trust (Fragouli, 2019) would be explained by leaders access to knowledge and making wise decisions.

Ultimately, the social results of realization of practical wisdom in public hospitals of the Ministry of Health can be the development of social capital because of improved social interactions and mutual trust in society due to wise behaviors and decisions of hospital managers, favorable feeling of support and accountability and preference of public interests over individual ones in the public sector. These results are in line with those of Hays (2008) on the effect of wisdom on the sense of social support and accountability, the ability to interact compassionately and without judgment with each other because of increased wisdom in society (Kramer, 2000), developing empathy and caring for others as a result of understanding wisdom (KordNoghabi et al., 2016) and preferring collective interests over personal ones in wise people and its benefits in society in Schwartz (2011).

Surely, this qualitative study has been difficult and time-consuming given the various focuses of attention and the multiplicity of definitions and related components, the lack of consensus on the subject examined, and the lack of strong theoretical foundations in Iran and even abroad, especially in the field of health. It has to be noted that this study does not claim to be universal, but one can claim that it has been able to conceptualize the issue of realizing managerial practical wisdom in public hospitals of the Ministry of Health of Iran based on Grounded theory. Each of the elements or variables presented in the model shows the significant areas considered in the paper, and it looks to be hard that such a study or model can balance the disciplines examined. Hence, using the opinions of those experts and researchers who are able to make changes in the titles and concepts, present or not show the different parts of the model and

41 
the relationship between them is very useful for us and we will welcome these comments eagerly.

The model can be refereed as a primary framework to top managers in the board of Hospitals to evaluate the decision making capabilities among managers. Especially due to management role taking by non-managers in hospitals, the provided model may be useful to help managers from different field of study to be effective in challenging situations. Additionally, the lack of both qualitative and quantitative tools in the assessments of managers wisdom shows the necessity of valid scales to be applied in promotion and hiring people. All in all, the model may help to view wisdom not as a concept in the literature but as a managerial feature which is applicable in the organizations.

\section{Summary}

Presenting a Model of Managerial practical wisdom in Hospitals This qualitative study was conducted to provide a model of managerial practical wisdom in public hospitals in order to define the components affecting managerial practical wisdom, development strategies and its results in hospitals based on interpretive paradigm using Grounded strategy and content analysis technique and based on paradigm model of Corbin and Strauss (2008). To this end, semi-structured interviews were conducted with 21 hospital managers, professors and experts in the field of health care management. The basic themes of the interviews during the data analysis and coding stage identify the central class, causal, contextual, intervening factors, strategies and consequences of managerial practical wisdom in the form of a paradigm model and finally to create Grounded theory about managerial practical wisdom in these hospitals. Accordingly, the dimensions and components of practical wisdom among the managers of the mentioned hospitals were cognitive abilities and managerial competencies, factors affecting its development including individual factors (personal experiences, personality pattern, and individual values) and organizational factors (spirituality at work, organizational values and organizational will).Moreover, the results of developing this type of wisdom among the mentioned managers can be categorized as individual results (mental and psychological well-being), organizational results (improving service quality, stakeholder satisfaction, 
organizational dynamism and agility, organizational vitality and organizational citizenship behaviors) and social outcomes (social capital development). These results can be used in the creation and development of quantitative tools for measuring managerial practical wisdom and as a qualitative complement in evaluating the quality of decisions among hospital managers.

Keywords: Wisdom Management; Practical Wisdom; Public Hospitals; Interpretive Paradigm.

JEL

Classification: G0; I18

\section{References}

Ardelt, M. (2000). Antecedents and effects of wisdom in old age: A longitudinal perspective on aging well.Research on Aging, 22(4), 360-394. Ardelt, M. (2003). Empirical assessment of a three-dimensional wisdom scale. Research on Aging, 25(3), 275-324.

Ardelt, M. (2009). How similar are wise men and women? A comparison across two age cohorts. Research in Human Development, 6(1), 9-26.

Ardelt, M. (2011). The measurement of wisdom: A commentary on Taylor, Bates, and Webster's comparison of the SAWS and 3D-WS. Experimental Aging Research, 37(2), 241-255.

Ardelt, M., \& Jeste, D. V. (2018). Wisdom and hard times: The ameliorating effect of wisdom on the negative association between adverse life events and well-being. The Journals Of Gerontology, Series B, 73(8), 1374-1383.

Aramoon, H., Feizy, T., \& Geramipour, M. (2018). Designing job embeddedness model using Grounded theory. Journal of Management of Public Organizations, 6(4), 119-136.

Asaadi, S., Amiri, Sh., Molavi, H., \& Bagheri, Kh. (2013). Introducing concept of wisdom in psychology and its educational applications. Journal of New Educational Approaches, 8(2), 1-28.

Aubrey, R., \& Cohen, P. M. (1995). Working Wisdom: Timeless Skills and Vanguard Strategies for Learning Organizations. Jossey-Bass Publishers, Inc., 350 Sansome Street, San Francisco, CA 94104.

Bachmann, C., Dierksmeier, C., \& Habisch, A. (2018). Practical Wisdom: Management's No Longer Forgotten VirtueJournal of Business Ethics, 153,147-165.

Baltes, P. B., \& Staudinger, U. M. (2000). Wisdom: A metaheuristic (pragmatic) to orchestrate mind and virtue toward excellence. American psychologist, 55(1), 122. 
Bangen, K. J., Meeks, T. W., \& Jeste, D. V. (2013). Defining and assessing wisdom: A review of the literature. The American Journal of Geriatric Psychiatry, 21(12), 1254-1266.

Barbuto, J. E., \& Wheeler, D. W. (2006). Scale development and construct clarification of servant leadership. Group $\mathcal{E}$ Organization Management, 31(3), 300-326.

Bazargan, A. (2008). Introduction to qualitative and mixed research methods: Common approaches in Behavioral Sciences. Tehran: Didar Publication.

Bergsma, A., \& Ardelt, M. (2012). Self-reported wisdom and happiness: An empirical investigation. Journal of Happiness Studies, 13(3), 481-499.

Bierly, P. E., Kessler , E. H., \& Christensen, E. W. (2000). Organizational learning, knowledge and wisdom. Journal of Organizational Change Management, 13(6), 595-618.

Birren, J. E., \& Fisher, L. M. (1990). 14 The elements of wisdom: overview and integration. Wisdom: Its Nature, Origins, and Development, 317.

Brown, S. C. (2004). Learning acrossthe campus: How college facilitates the development of wisdom. Journal of College Student Development, 45(2), 134-148.

Clayton, V. P., \& Birren, J. E. (1980). The development of wisdom across the life span: A reexamination of an ancient topic. Life-Span Development and Behavior, 3, 103-135.

Cloninger, C. R. (2012). Healthy personality development and well-being. World Psychiatry, 11(2), 103.

Corbin, J., \& Strauss, A. (2008). Basics of qualitative research: Techniques and procedures for developing grounded theory (3rd ed.). Thousand Oaks, CA: Sage Publications.

Creswell, J. (2012). Educational Research: Planning, Conducting, and Evaluating Quantitative and Qualitative Research (4rd ed.).Boston: Pearson Education.

Po Keung I. p. (2011). Practical wisdom of confucian ethical leadership: a critical inquiry", Journal of Management Development, 30(7), 685-696.

Danaeifard, H., \& Emami, S. M. (2007). Strategies of Qualitative Research: Reflections on Grounded Theory. Journal of Strategic Management Thought, 1(2), 67-97.

Danaeifard, H., Rajabzadeh, A., \& Salari, A. M. (2010). Beyond managerial knowledge and experience: An analysis of the elements forming management wisdom from the perspective of the NAJA Managers. Journal of Law Enforcement Management Studies, 5(3), 396-417.

Danaeifard, H., Alvani, S. M., \& Azar, A. (2012). Qualitative research methodology in management: a comprehensive approach. Tehran: Saffar Press.

Darville, J. (2019). Kinetic Leadership: Decision-making in Action. Management and Business Research Quarterly, 10, 13-24. https://doi. org/10.32038/mbrq.2019.10.03. 
Dickie, C. (2011). Coordinating Knowledge Hierarchies in Management: Re-conceptualising Organisational Wisdom. Philosophy of Management, 10(1), 79-94.

Dittman-Kohli, F., \& Baltes, P. B. (1990). Toward a neofunctionalist conception of adultintellectual development: Wisdom as a prototypical case of intellectual growth. Perspectives on Adult Growth, 54-78.

Fragouli, E. (2019). Employee Trust and Ethical Leadership Decision Making. Behavior Studies in Organizations, 1, 1-19. https://doi. org/10.32038/JBSO.2019.01.01.

Gibson, P. S. (2008). Developing practical management wisdom. Journal of Management Development, 27(5), 528-536.

Ghorbani, R., \& Khormaei, F. (2018). The Examining Causal Model of Wisdom: Explaining Effect of Personality and Coping Self-Efficacy. Social Psychology Research Journal, 8(31), 33-50.

Grossmann, I. (2017). Wisdom in context. Perspectives on Psychological Science, 12(2), 233-257.

Grossmann, I., Dorfman, A., \& Oakes, H. (2020). Wisdom is a socialecological rather than person-centric phenomenon. Current opinion in psychology, 32, 66-71.

Guba, E. G., \& Lincoln, Y. S. (1998). Fourth generation evaluation. CA: Sage Publications.

Hays, J. M. (2008). Dynamics of organisational wisdom. Journal of Global Strategic Management, 1(1), 17-35.

Holliday, S. G., \& Chandler, M. J. (1986). Wisdom: Explorations in adult competence. Contributions to Human Development.

Izak, M. (2013). The foolishness of wisdom: Towards an inclusive approach to wisdom in organization. Scandinavian Journal of Management, 29(1), 108115.

Jason, L. A., Reichler, A., King, C., Derryk, M., Camacho, J., \& Marchese, W. (2001).The measurement of wisdom: A preliminary effort. Journal of Community Psychology, 29(5), 585-598.

Kessler, E. H. (2006). Organizational wisdom: Human, managerial, and strategic implications. Group \& Organization Management, 31(3), 296-299.

Kessler, E. H., \& Bailey, J. R. (2007). Handbook oforganizational and managerial wisdom. CA: Sage Publications.

Kok, A. (2010). The adoption of digital learning tools in academy-industry partnerships. Procedia-Social and Behavioral Sciences, 2(2), 3693-3699.

KordNoghabi, R., \& Beiranvand, A. (2016).Implicit theories of wisdom in Iran: A phenomenological study. Journal of Islamic Psychology, 2(3), 78-105. KordNoghabi, R., Jahan, F., Rashid, Kh., \& Rezaei, A. (2016). Measure of wisdom in Iran (Introduction and validation of three scales). Quarterly of Educational Measurement, 6(22), 187-212. 
KordNoghabi, R., Karami, N., Beiranvand, A., E Nazari, N. (2018).The comparative study of wise behavior characteristics in Zal based on Ardelt's three dimensional wisdom model. Comparative Literature Research Journal (CLRJ), 6 (1), 1-30.

Kramer, D. A. (2000). Wisdom as a classical source of human strength: Conceptualization and empirical inquiry. Journal of Social and Clinical Psychology, 19(1), 83-101

Kunzmann, U. (2007). Wisdom: Adult development and emotionalmotivational dynamics.In R. Fernández-Ballesteros (Ed.), Geropsychology: European perspectives for an aging world, 224-338.

Kunzmann, U., \& Baltes, P. B. (2003). Wisdom-related knowledge: Affective, motivational, and interpersonal correlates. Personality and Social Psychology Bulletin, 29, 1104-1119.

Küpers, W. M. (2007). Phenomenology and Integral Pheno-Practice of Wisdom in Leadership and Organization. Social Epistemology, 21(2), 169193.

Levenson, M. R., Jennings, P. A., Aldwin, C. M., \&Shiraishi, R. W. (2005). Self-transcendence: Conceptualization and measurement.The International Journal of Aging and Human Development, 60(2), 127-143.

Limas, M. J., \& Hansson, R. O. (2004). Organizational wisdom. The International Journal of Aging and Human Development, 59(2), 85-103.

Malan, L. C., \& Kriger, M. P. (1998).Making sense of managerial wisdom. Journal of Management Inquiry, 7(3), 242-251.

Massingham, P. (2019).An Aristotelian interpretation of practical wisdom: the case of retirees. Palgrave Communications, 5(1), 1-13.

McKenna, B. (2005). Wisdom, ethics and the postmodern organization. In Handbook on the knowledge economy, edited by D. Rooney, G. Hearn, and A. Ninan. Cheltenham: Edward Elgar.

McKenna, B., Rooney, D. \& Boal, K. B. (2009). Wisdom principles as a metatheoretical basis for evaluating leadership. The Leadership Quarterly, 20(2), 177-190.

Medin, E.,Häkkinen, U., Linna, M., Anthun, K. S., Kittelsen, S. A., \& Rehnberg, C. (2013). International hospital productivity comparison: experiences from the Nordic countries. Health policy, 112(1-2), 80-87.

Pourdjam, M., Siadat, S. A., \& Rajaeepour, S. (2015). Structural Modeling for the Relationship of Organizational Wisdom and Archive of Strategic Intelligence. Journal of Studies in Education, 5(2), 238-251.

MonazamiTabar, F., KordNoghabi, R., Rashid, Kh., \& Yaghoobi, A. (2019). Construction and validation of the wisdom test based on Iranian components. Journal of Training Measurement, 9(36), 91-117.

Moradi, M. (2015). Design and development of wisdom-based organization model in government agencies. Journal of Public Management (Management Knowledge), 7(1), 185-209. 
Mousavi, M., Sarlak, M. A., Abasi, S., \& Moradi, M. (2013a). Assessment of Wisdom in The Various Levels of Government Agencies. World of Sciences Journal, 1(6), 122-134.

Mousavi, M., Sarlak, M. A., Abasi, S., \& Moradi, M. (2013b). Assessment and evaluation of organizational and managerial wisdom at various levels of public organizations with an attitude towards philosophical dimensions. Journal of Management Improvement, 7(21), 141-163.

Nonaka, I.,Chia, R., Holt, R., \& Peltokorpi, V. (2014). Wisdom, management and organization. London: Sage Publications.

Nonaka, I., \& Toyama, R. (2007). Strategic management as distributed practical wisdom (phronesis). Industrial and corporate chang, 16(3), 371-394. Paulhus, D. L.,Wehr. P., Harms, P. D., \& Strasser, D. I. (2002).Use of exemplar surveys to reveal implicit types of intelligence. Personality and Social Psychology Bulletin, 28(8), 1051-1062.

Pinheiro, P., \& Raposo, M. (2012). Measuring organizational wisdom applying an innovative model of analysis. Management Decision, 50(8), 1465-1487

Plickert, G., Kay, F., \& Hagan, J. (2017). Depressive symptoms and the salience of job satisfaction over the life course of professionals. Advances in Life Course Research, 31,22-33.

Rahmani, N., \& Dialameh, N. (2019). A wisdom-based leadership model from an Islamic perspective for educational organizations. Quarterly Journal of Applied Issues in Islamic Education, 4(3), 53-78.

Ranjbarian, B., Allameh, S. M., RashidKaboli, M., \& GholamiKarin, M. (2011). Analysis of the components of wisdom in Nahjul-Balaghah using content analysis. Journal of Public Administration Perspective, 2(1), 33-48.

Rezaeian, A., Nezafati, N., Otarkhani, A., \& Almswary, Kh. (2019). Designing and explaining organizational wisdom model. Research in Human Resources Management, Imam Husein Universit, 11(1), 117-142.

Reynolds, D. (2003). A study of US chief executive officers' managerial wisdom. Presented to the Faculty of Argosy University In Partial Fulfillment of The Requirements for the Degree of Doctor of Business Administration.

Rooney, D., \& McKenna, B. (2007). Wisdom in organizations: Whence and whither. Social Epistemology, 21(2), 113-138.

Schwartz, B. (2011). Practical wisdom andorganizations. Research in organizational behavior, 31, 3-23.

Schwartz, B., \& Sharpe, K. (2010). Practical wisdom: The right way to do the right thing. New york: Riverhead Books: 27-87.

Sohrabi, B., Shamizanjani, M., Elahi, Sh., \& Sherkat, M. H. (2013). Explanation of the factors affecting the erratically use of business information systems. Journal of Business Administration Researches, 5(10), 119-152.

47 
Staudinger, U. M. (1996). Wisdom and the social-interactive foundation of the mind. In Baltes, P. B., Staudinger, U. M. (Eds.), Interactive minds: Life-span perspectives on the social foundation of cognition, 276-318. Cambridge, England: Cambridge University Press.

Staudinger, U. M., Dörner, J., \& Mickler, C. (2005). Wisdom and Personality. In R. J. Sternberg \& J. Jordan (Eds.), Handbook of wisdom: Psychological perspectives. New York: Cambridge Uni-versity Press.

Staudinger, U. M., \& Glück. J. (2011). Psychological wisdom research: Commonalities and differences in a growing field. Annual review of psychology, 62, 215-241.

Staudinger, U. M., Lopez, D. F., \& Baltes, P. B. (1997). The psychometric location of wisdom-related performance: Intelligence, personality, and more? Personality and Social Psychology Bulletin, 23(11), 1200-1214.

Sternberg, R. J. (2003). WICS: A model of leadership in organizations. Academy of Management Learning E Education, 2(4), 386-401.

Sternberg, R. J. (2004). Words to the Wise about Wisdom?Human Development, 47(5), 286-289.

Sternberg, R. J. (2004). What is wisdom and how can we develop it? The Annals of the American Academy of Political and Social Science, 591(1), 164174.

Sternberg, R. J., Jarvin, L., \& Grigorenko, E. L. (2009). Teaching for wisdom, intelligence, creativity, and success. Thousand Oaks, CA: Corwin Press.

Takahashi, M., \& Bordia, P. (2000). The concept of wisdom: A crosscultural comparison. International journal of psychology, 35(1), 1-9.

Takahashi, M., \& Overton, W. F. (2005). Cultural foundations of wisdom: an integrated developmental approach. In R. J. Sternberg \& J. Jordan (Eds.), A handbook of wisdom: Psychological perspectives. Cambridge University Press.

Thomas, M. L., Bangen, K. J., Palmer, B. W. Sirkin, A., Avanzino, J., Depp, C. A., Glorioso, D., Daly, R. E., \& Jeste, D. V. (2017). A new scale for assessing wisdom based on common domains and a neurobiological model: The San Diego Wisdom Scale (SD-WISE). Journal of Psychiatric Research, 17(3), 18-45.

Webster, J. D. (2010). Wisdom and positive psychosocial values in young adulthood. Journal of Adult Development, 17(2), 70-80.

Wink, P., \& Helson, R. (1997). Practical and transcendent wisdom: Their nature and some longitudinal findings. Journal of Adult Development, 4(1), 1-15.

Yang, S. Y. (2001). Conceptions of wisdom among Taiwanese Chinese. Journal of Cross-cultural psychology, 32(6), 662-680.

Zaidman, N., \& Goldstein-Gidoni, O. (2011). Spirituality as a discarded form of organizational wisdom: Field-based analysis. Group $\mathcal{E}$ organization management, 36(5), 630-653. 